\title{
Changing Australian medicine names
}

\section{Jerry Yik \\ Policy analyst \\ The Society of Hospital \\ Pharmacists of Australia \\ Melbourne}

\section{Keywords}

adrenaline (epinephrine),

drug regulation,

International Non-

proprietary Names (INNs),

medication safety

Aust Prescr 2017:40:98-100

http://dx.doi.org/10.18773/ austprescr.2017.028

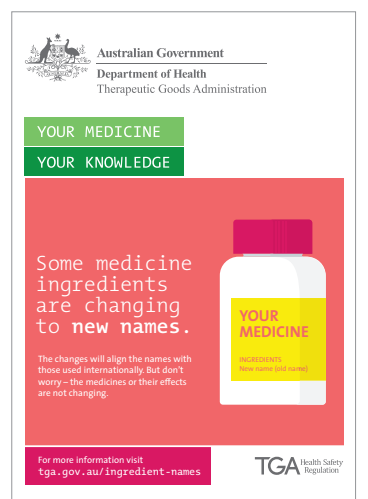

\section{SUMMARY}

The Therapeutic Goods Administration is changing the names of approximately 200 medicines.

The aim is to harmonise Australian medicine names with international names to reduce confusion and inconsistency, which ultimately improves medication safety and the quality use of medicines.

Most of the changes will have a four-year transitional arrangement. However, a short list of medicines has seven years to transition, with a requirement for dual labelling during this period.

Adrenaline and noradrenaline are special cases and will always be known as 'adrenaline (epinephrine)' and 'noradrenaline (norepinephrine)'.

Doctors, pharmacists and other health professionals, consumers, manufacturers, sponsors and companies providing services and programs to support the prescribing and administration of medicines, need to be aware of these changes.

\section{Introduction}

In 2013, the Therapeutic Goods Administration (TGA) announced its intentions to harmonise Australian drug names (active substance) and their excipients (inactive ingredients) with naming conventions abroad.' Australia has had its own system of naming drugs (Australian Approved Names - AANs). However from April 2016, the TGA has updated some medicine and ingredient names to be consistent with International Non-proprietary Names (INNs) wherever possible. The INN nomenclature system was developed by the World Health Organization (WHO) and has received Australian input. A four-year transition period will allow manufacturers, health professionals and patients to adjust to the changes.

\section{Why are drug names being changed?}

In the long term, making medicine names more consistent with nomenclature in other countries will provide clarity and reduce confusion for Australian consumers and health practitioners who travel internationally. It should also help those who trained or have practised overseas. The UK and New Zealand underwent the same process in 2003 and 2008.

The harmonisation of drug names allows the future approval of new AANs to be more closely monitored and aligned with INNs, to prevent potential confusion. There are short-term risks to changing drug names. The Australian Bureau of Statistics reports that almost $60 \%$ of consumers have less than adequate health literacy. ${ }^{2}$ Changes to medicine names can put people with low literacy at further risk of medication errors.

\section{Medicines and ingredients that are affected}

Approximately 200 drugs and 90 excipient names are affected, with some mentioned more than once due to having more than one salt. A full list of the affected medicines and excipients can be viewed on the TGA website. ${ }^{1}$

Changes to medicine names can be separated into five main categories (see Table). Adrenaline and noradrenaline have received special treatment. Due to their therapeutic use in anaphylaxis and life-threatening situations, the risk in changing the names completely to the INN nomenclature is too great in terms of safe prescribing, dispensing and administration. Adrenaline and noradrenaline will now always be known dually as 'adrenaline (epinephrine)' and 'noradrenaline (norepinephrine)'.

The transition for a selection of medicines that are either more frequently used or have a higher risk will take an additional three years, and dual labelling will be required. This will consist of the new INN name and the old approved name in parentheses afterwards. For example, 'frusemide' should be displayed as 'furosemide (frusemide)' until 2023, after which it will be just referred to as 'furosemide' (its INN nomenclature).

Many other changes are minor spelling differences or naming the hydration or salt for completeness and clarification in line with INN nomenclature. These changes will have a four-year transition period and do not require dual labelling. 


\section{Medicines and ingredients that are not affected}

Some medicine names will not change because the INN is already being used in Australia. Examples include paracetamol, glibenclamide and salbutamol in many other countries they are known as acetaminophen, glyburide and albuterol.

\section{Communicating the changes}

It is our responsibility as health professionals to convey these changes to patients to minimise confusion. The TGA has developed resources that can be displayed at GP clinics, pharmacies and hospitals to raise awareness. ${ }^{3}$

\section{Who will the changes affect?}

These changes go further than just affecting health practitioners and consumers. Resources such as the Australian Medicines Handbook, the Pregnancy and Breastfeeding Medicines Guide, and the Australian Injectable Drugs Handbook will need to consider the TGA's determination when reviewing their next editions.

As hospitals and health services make the transition to paperless systems and implement health information technology solutions and software, it is imperative that their service providers can show compliance with the TGA's new arrangements, as well as the national guidelines for on-screen display of clinical medicines information. ${ }^{4}$

On a larger scale, as state and territory governments have their own procurement and purchasing authorities, the request for tenders for the procurement of health information technology solutions must stipulate that they can comply with TGA's transitional and permanent changes with respect to medicine and excipient names.

Pharmaceutical companies that prepare medicines information will need to review the content to ensure it aligns with the updated medicine and excipient names during the transition period, and then again in 2020 or 2023 when the transitional arrangements expire.

The same goes for manufacturers of infusion pump devices, dispensing software and prescribing software companies, which will need to update their database of medicine names to comply with the TGA's new requirements. This can be an education tool for doctors and pharmacists who will see that the old name will no longer be available for selection at the point of prescribing and dispensing. It is also incumbent upon GPs and other health professionals

\section{Table Examples of changes to Australian drug names}

\begin{tabular}{|c|c|c|}
\hline Type of change & Current name & New name \\
\hline \multirow[t]{2}{*}{ Dual labelling until 2023} & frusemide & furosemide (frusemide) \\
\hline & lignocaine & lidocaine (lignocaine) \\
\hline \multirow{2}{*}{$\begin{array}{l}\text { Permanent drug labelling } \\
\text { change }\end{array}$} & adrenaline & adrenaline (epinephrine) \\
\hline & noradrenaline & noradrenaline (norepinephrine) \\
\hline Significant changes & insulin - human & insulin \\
\hline \multirow[t]{4}{*}{ Minor spelling changes } & amoxycillin & amoxicillin \\
\hline & cephalexin & cefalexin \\
\hline & cyclosporin & ciclosporin \\
\hline & oestradiol & estradiol \\
\hline \multirow[t]{2}{*}{ Hydration change only } & carbidopa anhydrous & carbidopa \\
\hline & codeine phosphate & codeine phosphate hemihydrate \\
\hline
\end{tabular}

who partake in e-health initiatives such as My Health Record and the National Prescription and Dispense Repository (NPDR) to use the correct medicine names.

\section{Other TGA changes}

At present, the TGA has also released new standards for labelling prescription and nonprescription medicine (TGO 91, TGO 92). ${ }^{5}$ Over a four-year transition period, these will replace existing requirements for medicine labelling (TGO 69). ${ }^{5}$

The new standards have more comprehensive requirements with respect to labelling of medicines packaging. This can present a challenge to medicines with small packages or very small containers (such as vials and ampoules), and for medicines that have an expanded name due to different salts, or that require dual labelling. They have provisions and exceptions for 'small containers' and 'very small containers' which ameliorate some of these concerns.

\section{Conclusion}

The move to harmonise Australian medicine names with international names is a welcome one. Although there is likely to be some short-term disruption during the transition, the longer term benefits of improved consistency and reduced confusion align with the principles of the quality use of medicines and medication safety. $\varangle$

Conflict of interest: none declared 
<ustralian Prescriber

\section{REFERENCES}

1. Department of Health. Therapeutic Goods Administration. Updating medicine ingredient names - list of affected ingredients [Internet]. 2016 Nov 28. Canberra: Commonwealth of Australia; 2016. www.tga.gov.au/updating-medicineingredient-names-list-affected-ingredients [cited 2017 May 1]

2. Australian Bureau of Statistics. Health literacy. 4102.0 Australian Social Trends, June 2009 [Internet]. Canberra: Australian Bureau of Statistics; 2009. http://www.abs.gov.au/ AUSSTATS/abs@.nsf/Lookup/4102.0Main+Features20June+ 2009 [cited 2017 May 1]

3. Department of Health. Therapeutic Goods Administration. Updating medicine ingredient names [Internet]

2016 Nov 28. Canberra: Commonwealth of Australia; 2016.

www.tga.gov.au/updating-medicine-ingredient-names [cited 2017 May 1]
4. Australian Commission on Safety and Quality in Health Care. Electronic medication management (EMM) [Internet] Sydney: ASCQHC; 2017. https://www.safetyandquality.gov.au/ our-work/medication-safety/electronic-medicationmanagement-systems/ [cited 2017 May 1]

5. Department of Health. Therapeutic Goods Administration. Medicine labels: guidance on TGO 91 and TGO 92.

2016 Aug 17 [Internet]. Canberra: Commonwealth of Australia; 2016. www.tga.gov.au/medicine-labels-guidancetgo-91-and-tgo-92 [cited 2017 May 1] 